\title{
Pemberdayaan dan Pembentukan Kelompok Peduli Diabetes Melitus Pada Kader Masyarakat di Wilayah Kelurahan Menganti
}

\author{
Engkartini ${ }^{1}$, Rully Andika ${ }^{2}$, Lia Febriani $^{3}$ \\ Prodi D3 Keperawatan ${ }^{1}$, Prodi S1 Keperawatan ${ }^{2,3}$ \\ STIKES Al-Irsyad Al-Islamiyyah, Jalan Cerme No 24 Sidanegara Cilacap 53223 \\ Email korespondensi: engkar_06@yahoo.com
}

\begin{abstract}
Abstrak
Diabetess mellitus (DM) merupakan penyakit dengan peningkatan kadar gula darah melebihi kadar normal disebabkan oleh kekurangan hormon insulin akibat ketidakmampuan kelenjar pankreas memproduksi insulin secara maksimal (Hastuti, 2008; Wicaksono, 2011). Menurut survei yang dilakukan oleh World Health Organization (WHO), jumlah penderita DM di Indonesia pada tahun 2000 terdapat 8,4 juta orang dan menempati urutan ke-4 terbesar di dunia. Secara epidemiologi, diperkirakan bahwa pada tahun 2030 prevalensi DM di Indonesia mencapai 21,3 juta orang (Diabetess Care, 2004). Kabupaten Cilacap termasuk dengan kasus DM yang banyak salah satu wilayah di kabupaan Cilacap yang banyak susu DM yaitu desa Menganti Meningkatnya kasus DM karena kurangnya kesadaran atau gejala awal penderita DM. Tujuan pengabdian ini adalah meningkatkan pengetahuan kader tentang penyakit DM dan pembentukan kelompok peduli DM. metode yang digunakan yaitu pemberian materi, role play dan musyawarah Hasil dari pre-test dan post-test terjadi peningkatan pengetahuan kader dan keterampilan tentang pemeriksaan kadar gula darah serta terbentuk kelompok peduli DM
\end{abstract}

Kata Kunci: Diabetes Melitus Pemberdayaan , Kelompok

\begin{abstract}
Diabetess mellitus (DM) is a chronic disease in the endocrine system characterized by an increase in blood sugar levels beyond normal levels caused by a deficiency in the hormone insulin due to the inability of the pancreas gland to produce insulin optimally (Hastuti, 2008; Wicaksono, 2011). According to a survey conducted by the World Health Organization (WHO), the number of DM sufferers in Indonesia in 2000 there were 8.4 million people and it is the 4th largest in the world. Epidemiologically, it is estimated that in 2030 the prevalence of DM in Indonesia will reach 21.3 million people (Diabetess Care, 2004). Increased cases of DM due to lack of awareness or early symptoms of DM. The aim of this service is to increase cadres' knowledge about DM disease and the formation of DM care groups. The results of the ppretest and post test showed an increase in the knowledge of cadres and skills about checking blood sugar levels and a DM care group was formed
\end{abstract}

Keywords: DM, empowerment, groups 


\section{PENDAHULUAN}

Diabetess mellitus (DM) merupakan penyakit kronik pada sistem endokrin yang ditandai dengan adanya peningkatan kadar gula darah melebihi kadar normal disebabkan oleh kekurangan hormon insulin akibat ketidakmampuan kelenjar pankreas memproduksi insulin secara maksimal ( (Wicaksono, 2011)DM merupakan masalah kesehatan nasional yang dihadapai masa sekarang ini karena berdasarkan data dari Kementerian Kesehatan RI tahun 2010 diabetess melitus mengalami peningkatan setiap tahunnya.

Menurut survei yang dilakukan oleh World Health Organization (WHO), jumlah penderita DM di Indonesia pada tahun 2000 terdapat 8,4 juta orang dan menempati urutan ke4 terbesar di dunia. Secara epidemiologi, diperkirakan bahwa pada tahun 2030 prevalensi DM di Indonesia mencapai 21,3 juta orang (Care, 2004)

Berdasarkan (Kemenkes RI, 2018), DM terus meningkat tiap tahunnya. Pada tahun 2013, DM meningkat sebesar 2,1 \% dari tahun 2007 dengan prevalensi usia $\quad \geq 15$ tahun. Prevalensi penyakit diabetes berdasarkan diagnosis tenaga kesehatan sebesar $0,8 \%$, secara keseluruhan adalah 1,3\% dan prevalensi tertinggi terdapat di Kabupaten Cilacap (3,9\%), diikuti Kabupaten Tegal Kota (3,1\%), Surakarta (2,8\%), dan Pemalang (2,1\%) (Riskesda, 2007)

DM telah menjadi penyebab dari 4,6 juta kematian dan pengeluaran biaya kesehatan untuk DM telah mencapai 6, 5 triliun rupiah (Trisnawati \& Setyorogo, 2013). Hasil Riset Kesehatan Dasar (Riskesda) tahun 2007, diperoleh bahwa proporsi penyebab kematian akibat DM pada kelompok usia 45-54 tahun di daerah perkotaan menduduki ranking ke-2 yaitu 14,7\% (Rohmah, Bakar, Wahyuni, 2012). Data dari Dinas Kesehatan Cilacap tahun 2015 kasus DM di kabupaten Cilacap tercatat sebanyak 3.025 dengan 374 DM tipe 1 dan 2.651 merupakan Diabetes Militus tipe 2. Penyebaran kasus DM tipe 2 di Kabupaten Cilacap terbanyak di wilayah Puskesmas Cilacap Tengah 1, dan di Puskesmas Kesugihan1.

Berdasarkan hal tersebut, maka tim dosen STIKES Al-Irsyad Al-Islamiyyah Cilacap bermaksud melakukan Pemberdayaan Dan Pembentukan Kelompok Organisasi Peduli DM Pada Kader Masyarakat Di Wilayah Kelurahan Menganti

\section{MASALAH}

Berdasarkan hasil observasi di lapangan, wawancara dengan kader masyarakat sebagian besar belum memahami secara pasti apa tanda dan gejala diabetes, faktor resiko, 
penatalaksanan pencegahan terjadinya penyakit DM dan kasus yang terjadi di wilayah desa Menganti serta kelompok yang peduli terhadap kasus penyakit DM. Salah satu upaya preventif yang akan diberikan oleh tim pengusul melakukan Pemberdayaan Dan Pembentukan Kelompok Peduli DM Pada Kader Masyarakat Di Wilayah Kelurahan Menganti.

\section{METODE}

Berdasarkan analisis situasi dan permasalahan di atas tim pengusul kegiatan Pengabdian Masyarakat berkeinginan membantu masyarakat dalam mengenali tanda dan gejala DM agar dapat melakukan tindakan pencegahan DM. Kegiatan pengabdian dilakukan denga melalui beberapa tahap yaitu:

1) Koordinasi dengan pihak Puskesmas dan kepala desa Menganti.

2) Pemberian materi tentang DM kepada kader desa Menganti. Kegiata ini diawali dan diakhiri dengan pre test dan post test untuk mengukur tingkat pemahaman kader terhadap materi yang diberikan.

3) Pemberian keterampilan tentang cara deteksi dini gejala DM dan pemeriksaan glukosa darah.

4) Pembentukan kelompok peduli DM dengan anggota inti adalah para kader desa Menganti. Tugas dari kelompok ini adalah untuk mengkoordinir pelaksanaan deteksi awal penyakit DM di masyarakat Menganti. Kelompok ini melakukan tugasnya di bawah pengawasan kepala desa Menganti dan Puskemas Kecamatan Kesugihan 2.

\section{HASIL DAN PEMBAHASAN}

\section{1) Hasil}

Pelaksanaan program pengabdian kepada masyarakat terkait dengan Pemberdayaan Dan Pembentukan Kelompok Peduli DM Pada Kader Masyarakat Di Wilayah Kelurahan Menganti telah dilaksaankan pada : Hari/tanggal Rabu, 29 Juli 2020, bertempat di Balai desa Menganti, pukul 09.00-13.00 WIB, jumlah peserta 21 orang. Pelaksaan kegiatan pengabdian dilaksanakan dengan : Pertama pemberian kuesioner pre test pengetahuan tentang DM kepada kader yang datang di acara pengabdian masyarakat yang bertujuan untuk mengukur tingkat pengetahuan kader dan hasilnya rata 6,8.; Kedua pemaparan materi terkait DM yang disampaikan oleh ketua kelompok pengabdian yaitu Engkartini. Ketiga demostrasi pengecekan kadar gula darah yang bertujuan untuk meningkatkan ketrampilan kader dalam melakukan pengecekan kadar gula 
darah; Keempat yaitu pembentukan kelmpok peduli DM yang bertujuan untuk memudahkan berkoordinasi dalam mengatasi masalah penyakit DM yang didapatkan ketua bu Kartisen ; sekertaris bu Suri ; bendahara bu Sutriyah; Evaluasi kader yaitu dengan kader mampu menjelaskan tentang konsep DM dan dapat melakukan praktek pemeriksaan kadar gula darah secara mandiri; Monitoring pelaksaan dilakuakn 1 minggu setalah dilakukan pengabdian yaitu dengan melihat hasil pemeriksaan gula darah yang dilakukan oleh kader.

\section{2) Pembahasan}

Berdasarkan hasil pengabdian didapatkan bahwa ada peningkatan pengetahuan tentang penyakit DM. Hal tersebut terjadi karena dilakukan perlakuan atau treatmeant berupa pendidikan kesehatan tetang penyakit DM. Dari hasil post-test menunjukkan bahwa rata-rata tingkat pengetahuan kader tentang DM setelah pendidikan kesehatan meningkat/ lebih tinggi dibanding rata-rata sebelum penyuluhan. Perbedaan ini bermakna bahwa perlakuan yang berupa penyuluhan dapat meningkatkan pengetahuan responden tentang penyakit DM dan adanya keterampilan dari kader tentang pengecekan kadar gula darah.

Penyuluhan kesehatan adalah kegiatan pendidikan kesehatan yang dilakukan dengan menyebarkan pesan dan menanamkan keyakinan bertujuan agar masyarakat lebih tahu, sadar, serta bisa melakukan suatu anjuran yang diberikan ada hubungannya dengan kesehatan. Adanya peningkatan tingkat pengetahuan kader tentang DM setelah diberikan pendidikan kesehatan juga didukung oleh beberapa hal antara lain tingkat pengetahuan kader sebelum pendidikan kesehatan sebagian besar memang sudah memiliki pengetahuan cukup karena DM merupakan masalah penyakit yang terus meningkat angka kejadiannya dan tidak diketahui ketika masih dalam tahap awal penyakit ini timbul. Pengetahuan yang pernah didapatkan dan disimpan dalam memori kader kemudian dimunculkan kembali melalui pendidikan kesehatan melalui Pendidikan kesehatan yang diberikan kader kepada keluarga penderita DM.

Menurut (Bimo, 2004), bahwa untuk menimbulkan kembali memori yang telah disimpan akan lebih baik dengan menggunakan rangsangan objek yang harus diingat. Dalam hal ini, pendidikan kesehatan memberikan rangsangan sebagai objek harus diingat kembali sekaligus juga memberikan input baru yang menambahkan atau meluruskan memori yang telah disimpan.

Penyuluhan kesehatan tentang DM merupakan tahap awal bertambahnya wawasan atau pengetahuan seseorang yang dapat membentuk sikap dalam kewaspadaan terhadap penyakit DM terutama pada lansia. Dengan sering diadakan penyuluhan kesehatan yang menarik dan mudah difahami dapat menambah pengetahuan ibu kader yang baik tentang DM maka akan 
direspon secara positif oleh kader dengan sikapnya terlebih dahulu sebelum diwujudkan dalam bentuk perilaku (practice). Demikian juga semakin jarang diadakan penyuluhan kesehatan, pengetahuan kader tentang penyakit DM maka sebagian besar juga memiliki pandangan yang kurang tentang penyakit DM . Dengan demikian semakin sering diadakan penyuluhan kesehatan tentang pencegahan dan penatalaksanaan penyakit DM maka memiliki peran dalam menentukan pengetahuan yang lebih baik dan didalam menentukan sikap yang semakin positif dalam penangan kasus DM.

Pembetukan kelompok merupakan sekumpulan individu dengan karakteristik tertentu dan kesamaan identitas yang saling berinteraksi bersama serta memiliki kesadaran kolektif sebagi satu kesatuan. Tujuan pembentukan kelompok ini yaitu supaya ada kesadaran dalam kader masyarakat yang mempunyai tujuan yang sama untuk peduli terhadap penyakit DM yang kasusnya masih bertambah. Kepedualian kelompok ini berupa dari deteksi dini pada masyarakat terhadap adanya kemungkinan terjadinya DM dan pengendalian serta pencegahan terjadi komplikasi pada pasien DM di lingkungan masyarakat Menganti.

\section{KESIMPULAN}

Pengabdian masyarakat yang dilaksanakan oleh para dosen STIKES Al-Irsyad AlIslamiyyah Cilacap berupa pemberdayaan masyarakat dan pembentukan kelompok peduli DM di kader Masyarakt desa Menganti dapat terselenggara dengan baik dan lancar sesuai dengan jadwal yang direncanakan. Dari kegiatan penyajian materi, diskusi, pelatihan dan pembentukan kelompok dapat dipantau adanya peningkatan wawasan, pemahaman kemampuan para peserta serta terbentuknya kelompok peduli penyakit DM.

Berdasarkan manfaat dan hasil yang diperolah, maka disarankan kegiatan ini tidak berhenti sampai disini, namun perlu kegiatan lanjutan berupa pendampingan dan pemantauan lebih lanjut tentang kinerja kader dan peningkatan pengetahuan tentang pencegahan komplikasi penyakit DM

\section{DAFTAR PUSTAKA}

Bimo, W. (2004). Pengantar Psikologi Umum. Andi Offset.

Care, D. (2004). Diabetes in the UK. 
Kemenkes RI. (2018). Hasil Utama Riset Kesehatan Dasar Tahun 2018. Kementrian Kesehatan Republik Indonesia. https://doi.org/1 Desember 2013

Riskesda. (2007). Laporan Riset Kesehatan Dasar.

Trisnawati \& Setyorogo. (2013). jurnal ilmiah kesehatan. Jurnal Ilmiah Kesehatan, 5.

Wicaksono, R. P. (2011). Faktor-faktor yang berhubungan dengan kejadian Diabetes Mellitus II. 